\title{
Convective Heat Transfer Coefficient in a Packed Bed of Rice
}

\author{
A.H. ZAHED and R.P. SINGH \\ Department of Chemical Engineering, King Abdulaziz University, \\ Jeddah, Saudi Arabia; and \\ Department of Agricultural Engineering, \\ University of California, Davis, California, USA.
}

\begin{abstract}
A new equation for the heat transfer coefficient was developed by comparing the experimental data to the numerical solution of the heat balance equations for both rice and air. A comparison was made between the Wang et al. equation and the equation developed in this research. The latter equation was used in the simulation of the concurrent-flow rice dryer.
\end{abstract}

\section{Introduction}

The convective heat transfer coefficient is an important property in drying rate simulation, since air temperature varies with this coefficient.

Barker ${ }^{[1]}$ presented a thorough review of heat transfer in packed beds. Correlations were given for heat transfer coefficients in beds of randomly packed spheres, spheres in ordered arrays, and cylinders in commercial packings.

Henderson and Pabis ${ }^{[2]}$ developed a correlation equation for the heat transfer coefficient from Treybal's data ${ }^{[3]}$. Boyce ${ }^{\mid 4]}$ studied the convective heat transfer coefficient of a thin layer of barley and developed an equation for volumetric heat transfer coefficient given by O'Callaghan et al. ${ }^{[5]}$.

Bernard et al. ${ }^{[6]}$ studied heat mass and momentum transfer in the flow of gases through granular solids. Correlations were given for heat, mass transfer coefficients, and pressure drop in the direction of flow. They also concluded that the heat transfer coefficient was independent of shape, wetness of surfaces and interstitial configuration.

Schumann ${ }^{[7]}$ formulated and solved the complicated theoretical heat transfer rate equations for the simple case of an incompressible fluid passing uniformly through a 
bed of solid particles with perfect conductivity. In his analysis, Schumann made some assumptions, and based on these assumptions, he derived two equations relating the solid and fluid temperatures to the heat transfer coefficient.

Thomas and Harold ${ }^{[8]}$ reviewed the literature concerned with fluid particle heat transfer in packed and moving beds. Practical working equations for the solution of problems involving this type of heat transfer were developed. These equations are valid for gas temperature ranges of $38^{\circ} \mathrm{C}$ to $816^{\circ} \mathrm{C}$, particle diameter of 2.1 to $3.8 \mathrm{~cm}$, and gas mass flow rates of 293 to $5859 \mathrm{~kg} / \mathrm{h}-\mathrm{m}^{2}$. The equations are restricted to solids with the same general particle characteristics as sized gravel, refractory pebbles, and anthracite coal. Thomas and Harold ${ }^{[8]}$ also concluded, for the case of heating pebbles with hot gas, that below a solid-gas ratio of 1.5 there is a relatively small effect of the ratio $\left(R_{a}\right)$ on the heat transfer coefficient, where

$$
R_{a}=\frac{W_{s} C_{s}}{W_{a} C_{a}}
$$

where

$C_{a}=$ Specific heat of dry air, $\mathrm{kJ} / \mathrm{kg}-{ }^{\circ} \mathrm{C}$

$C_{s}=$ Specific heat of solid, $\mathrm{kJ} / \mathrm{kg}-{ }^{\circ} \mathrm{C}$

$R_{a} \quad=$ Solid-Gas ratio defined in Equation (1)

$W_{o} \quad=$ Weight rate of fluid, $\mathrm{kg} / \mathrm{h}$

$W_{s} \quad=$ Weight rate of solid, $\mathrm{kg} / \mathrm{h}$

Wang et al..$^{[9]}$ formulated an equation to predict the convective heat transfer coefficient in a packed bed of medium grain rough rice. The equation found by comparing the experimental data to the Schumann's curves, was reported as

$h_{c}=0.00718 G_{a}^{1.2997}$

Walker ${ }^{[10]}$ used an equation of the form

$h_{c}=0.672 G_{a}^{0.4899}$

for the concurrent drying simulation of long grain rough rice,

where:

$G_{a}=$ air flow rate, $\mathrm{kg} / \mathrm{m}^{2}-\mathrm{h}$

$h_{c}=$ convective heat transfer coefficient, $\mathrm{kJ} / \mathrm{m}^{2}-{ }^{\circ} \mathrm{C}-\mathrm{h}$

\section{Mathematical Development}

The rate of heat transfer from air to grain is controlled by the convective heat transfer coefficient. The actual value of heat transfer for a packed bed of grain is important in drying calculations.

In this section, a heat transfer coefficient equation was developed by comparing the experimental data to the numerical solution of the heat balance equations for both rice and air.

In the study of heat transfer of a packed bed of rice, one can write heat balance 
equations for both air and rice, as follows:

$$
\begin{gathered}
\frac{\partial T_{a}}{\partial x}=\frac{-h_{c} a\left(T_{a}-T_{p}\right)}{G_{a} C_{a}+G_{a} C_{v} H} \\
\frac{\partial T_{p}}{\partial t}=\frac{h_{c} a\left(T_{a}-T_{p}\right)}{\rho_{p} C_{p}+\rho_{p} C_{w} \bar{M}}
\end{gathered}
$$

where:

$$
\begin{array}{ll}
a & =\text { Particle surface area per unit volume, } \mathrm{m}^{2} / \mathrm{m}^{3} \\
C_{p} & =\text { Specific heat of dry grain kernel, } \mathrm{kJ} / \mathrm{kg}-{ }^{\circ} \mathrm{C} \\
C_{v} & =\text { Specific heat of water vapor, } \mathrm{kJ} / \mathrm{kg}-{ }^{\circ} \mathrm{C} \\
C_{w} & =\text { Specific heat of liquid water, } \mathrm{kJ} / \mathrm{kg}-{ }^{\circ} \mathrm{C} \\
H & =\text { Absolute humidity, } \mathrm{kg} / \mathrm{kg} \\
\bar{M} & =\text { Average moisture content, dry basis (decimal) } \\
t & =\text { Time, } \mathrm{hr} \\
T_{a} & =\text { Air temperature, }{ }^{\circ} \mathrm{C} \\
T_{p} & =\text { Grain temperature, }{ }^{\circ} \mathrm{C} \\
x & =\text { Variable bed coordinate, } \mathrm{m} \\
\rho_{p} & =\text { Density of dry grain kernel, } \mathrm{kg} / \mathrm{m}^{3} .
\end{array}
$$

The following assumptions were used in developing the above equations ${ }^{[1,12]}$ :

- Heat exchange between an interfacing gas and solid particles takes place mainly by convection.

- No appreciable volume shrinkage occurs during the heating process.

- Particle-to-particle conduction is negligible.

- $\partial H / \partial x$ is negligible compared to $\partial T_{u} / \partial x$; and $\partial H / \partial t$ is also negligible compared to $\partial T_{p} / \partial t$.

- The variation of thermal properties of air is negligible for the temperature range involved.

- The temperature change of the moving air due to evaporation of water vapor into the air stream is negligible.

- In heating and surface drying for short duration, one can neglect the mass transfer effect.

One can also ignore the terms $G_{a} C_{v} H$ and $\rho_{p} C_{n} \bar{M}$ since they are small in comparison to the term with which they are summed. If we let $G_{a}=V_{0} \rho_{a}, C_{a v}=C_{a} \rho_{a}$, and $\dot{h}=h_{c} a$, equations (4) and (5) take the following form, respectively:

$$
\frac{\partial T_{a}}{\partial x}=\frac{-\dot{h}\left(T_{a}-T_{p}\right)}{V_{0} C_{a v}}
$$

where:

$C_{a v}=$ Volumetric specific heat of air, $\mathrm{kJ} / \mathrm{m}^{3}-{ }^{\circ} \mathrm{C}$

$\dot{h}^{a v}=$ Volumetric heat transfer coefficient, $\mathrm{kJ} / \mathrm{m}^{3}-{ }^{\circ} \mathrm{C}-\mathrm{h}$

$V_{0} \quad=$ Air velocity, $\mathrm{m} / \mathrm{h}$ 
and

$$
\frac{\partial T_{p}}{\partial t}=\frac{\dot{h}\left(T_{a}-T_{p}\right)}{\rho_{p} C_{p}}
$$

Equations (6) and (7) could be solved by a numerical method, with the boundary and the initial conditions as:

$$
\begin{gathered}
T_{a}(x=0, \mathrm{t})=T_{a 0} \\
T_{a}(x, t=0)=T_{a 0} \\
\mathrm{~T}_{\mathrm{p}}(x, t=0)=T_{p 0}
\end{gathered}
$$

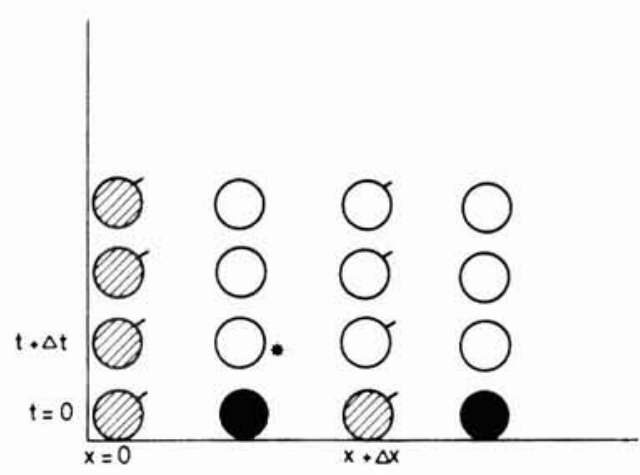

FIG.1. Air and grain temperature.

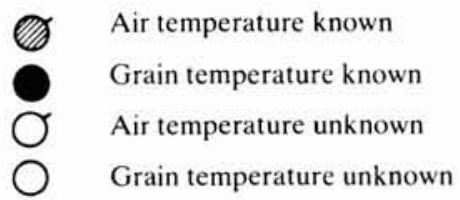

Consider Fig. 1, which shows the grain and air temperature. By using the finite difference for $\frac{\partial T_{a}}{\partial x}$ and $\frac{\partial T_{p}}{\partial t}$ at the sign $\left({ }^{*}\right)$ one can get

$$
\left.\frac{\partial T_{a}}{\partial x}\right|_{*}=\frac{T_{a_{t+\Delta t}}^{x+\Delta x}-T_{a_{t+\Delta t}}^{x}}{\Delta x}
$$

and

$$
\left.\frac{\partial T_{p}}{\partial t}\right|_{*}=\frac{T_{p_{t+\Delta t}}^{x+\Delta x / 2}-T_{p_{t}}^{x+\Delta x / 2}}{\Delta t}
$$

Substitute Equation (11) into Equation (7) 


$$
T_{p_{t+\Delta t}}^{x+\Delta x / 2}-T_{p_{t}}^{x+\Delta x / 2}=\frac{\Delta t \dot{h}}{\rho_{p} C_{p}}\left(T_{a_{t}+\Delta t}^{x+\Delta x / 2}-T_{p_{t}+\Delta t}^{x+\Delta x / 2}\right)
$$

Let

$$
C_{p \nu}=\rho_{p} C_{p}, A_{1}=\frac{\Delta t \dot{h}}{C_{p v}}
$$

and take

$$
T_{a_{t+\Delta t}^{x+\Delta x / 2}}^{x+1 / 2}\left(T_{a_{t+\Delta t}^{x+\Delta x}}^{x}+T_{a_{t+\Delta t}}^{x}\right)
$$

By substituting Equation (13) into Equation (12) and arranging this, one can get:

$$
T_{p_{t+\Delta t}+\Delta x / 2}^{x+\Delta}=B_{1}\left[T_{p_{t}}^{x+\Delta x / 2}+A_{1} / 2\left(T_{a_{t+\Delta t}^{x+\Delta x}}+T_{a_{t+\Delta t}}^{x}\right)\right]
$$

For the air temperature equation, substitute Equation (10) into Equation (6):

$$
T_{a_{t+\Delta t}}^{x+\Delta x}-T_{a_{t+\Delta t}}^{x}=\frac{-\dot{h} \Delta x}{C_{a v} V_{0}}\left(T_{a_{t+\Delta t}}^{x+\Delta x / 2}-T_{p_{t+\Delta t}+\Delta x / 2}^{x}\right)
$$

By substituting Equation (14) into Equation (15), and after some rearrangement, one obtains:

$$
\begin{aligned}
T_{a_{t+\Delta t}}^{x+\Delta x} & \left(1+A_{2} / 2-\frac{A_{2} B_{1} A_{1}}{2}\right)=T_{a_{t+\Delta t}}^{x} \\
& \left(1-\frac{\mathrm{A}_{2}}{2}+\frac{\mathrm{A}_{2} \mathrm{~B}_{1} \mathrm{~A}_{1}}{2}\right)+T_{p_{t}}^{{ }^{+}+\Delta x / 2}\left(A_{2} B_{1}\right)
\end{aligned}
$$

where

$$
A_{2}=\dot{h} \Delta x / V_{0} C_{a v}, B_{1}=1 /\left(1+A_{1}\right)
$$

To simplify Equation (16), one can define

$$
\begin{aligned}
& C_{1}=1+\frac{A_{2}}{2}-\frac{A_{2} B_{1} A_{1}}{2} \\
& C_{2}=1-\frac{A_{2}}{2}+\frac{A_{2} B_{1} A_{1}}{2} \\
& C_{3}=A_{2} B_{1}
\end{aligned}
$$

Substituting $C_{1}, C_{2}$ and $C_{3}$ into Equation (16) one can get

$$
T_{a_{t+\Delta t}^{x+\Delta x}}^{x+1 / C_{1}}\left(C_{2} T_{a_{t+\Delta t}^{x}}^{x}+C_{3} T_{p_{t}}^{x+\Delta x / 2}\right)
$$

By using the data of the experiments performed by Wang ${ }^{[13]}$, one can compare the numerical solutions of Equations (14) and (17) to the above-mentioned Wang's data. 
This method is to find the best heat transfer coefficient that minimized the following equation.

$$
S=\sum_{t_{i}}\left(T_{\text {exp }}-T_{a}\right)_{x_{1}}^{2}+\sum_{t_{i}}\left(T_{\text {exp }}-T_{a}\right)_{x_{2}}^{2}
$$

where

$$
\begin{aligned}
& t_{i}=\text { Corresponding time steps, minutes } \\
& x_{1}=5 \mathrm{~cm}, \text { First depth } \\
& x_{2}=15 \mathrm{~cm}, \text { Second depth }
\end{aligned}
$$

After the minimizing procedure for all the experimental data at the two depths, 5 $\mathrm{cm}$ and $15 \mathrm{~cm}$, a heat transfer coefficient equation was developed as:

$$
h_{c}=1.7 \times 10^{-5} G_{a}^{2.023}
$$

\section{Results and Discussion}

A comparison between Equation (2) and (19) is shown in Fig. 2. From Fig. 2, one can see that there is a big difference between Equations (2) and (19). In order to examine the effect of this difference between Equations (2) and (19) on the theoretical concurrent flow moisture contents and grain temperatures, a concurrent flow drying computer program was used to obtain the moisture content and the grain temperature. In the concurrent flow drying computer program, Equation (2) was used for one run, and Equation (19) was used for the second run.

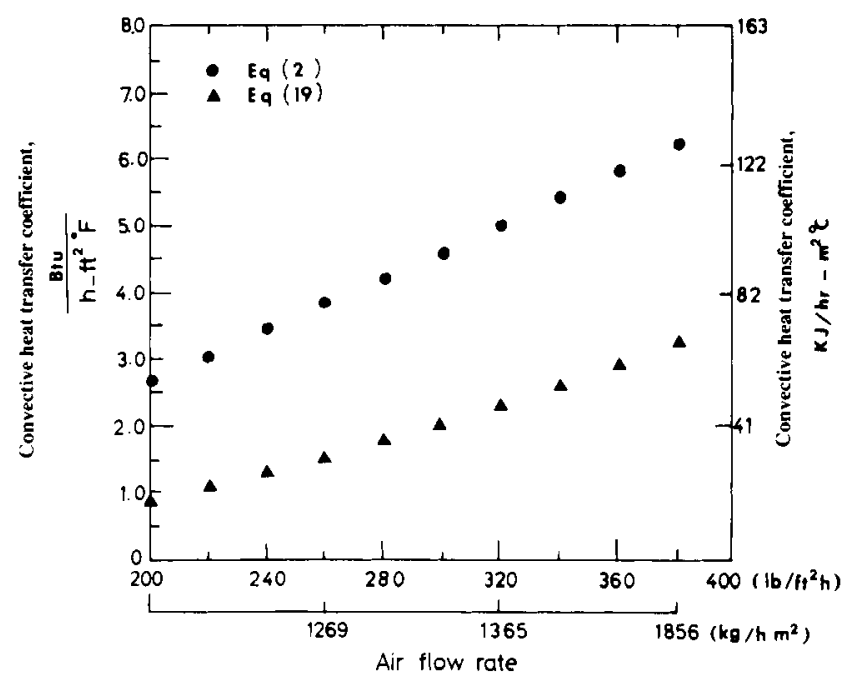

FIG. 2. Comparison between equations (2) and (19).

The results from the above analysis are shown in Fig. (3) and (4). From the former figure, one can see that there is no significant difference in the moisture content removed, but from the latter figure, it can be observed that the maximum product 
temperature is $4 \%$ higher when Equation (2) is used for the heat transfer coefficient, instead of Equation (19). However, the statistical analyses from Zahed ${ }^{[14]}$ show that there is no significant difference between the results obtained by using Equation (2) or (19) on concurrent drying simulation of medium rough rice.



FIG. 3. Theoretical concurrent moisture content. The heat transfer coefficient equation (2) was used for one run, and equation (19) was used for the second run. The inlet conditions are: $M_{0}=22.9 \%$ w.b., inlet grain temperature $14.4^{\circ} \mathrm{C}$, air flow rate $26 \mathrm{~m}^{3} / \mathrm{m}^{2}-\mathrm{min}$, grain flow rate $2.12 \mathrm{~m}^{3} / \mathrm{m}^{2}-\mathrm{h}$.

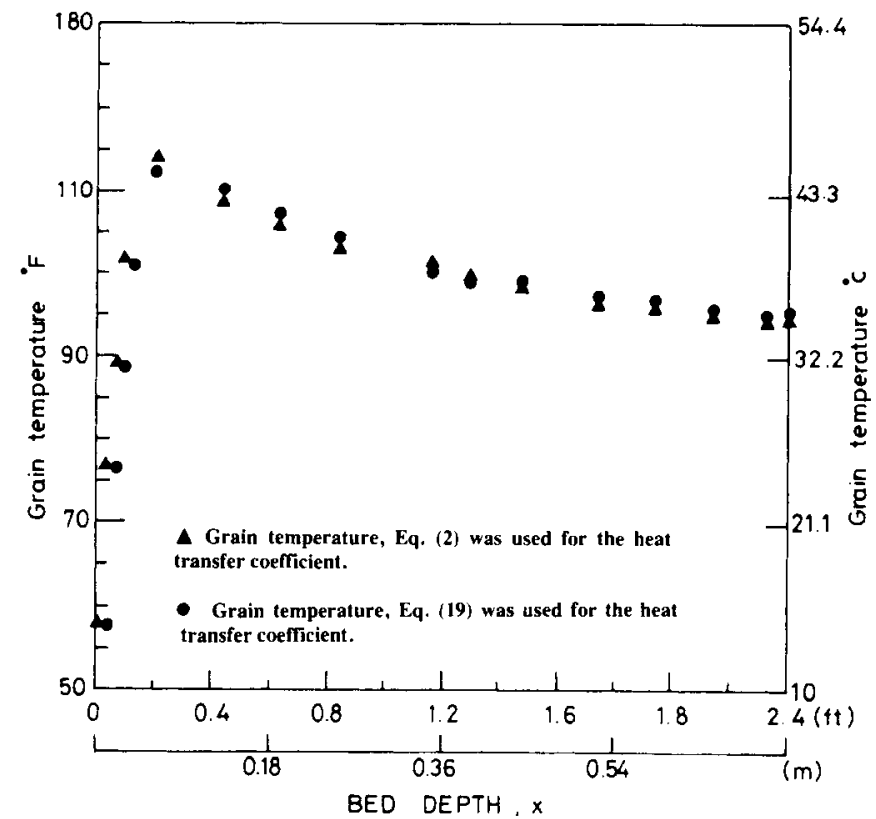

FIG. 4. Theoretical concurrent rice temperature. The heat transfer coefficient equation (2) was used for one run, and equation (19) was used for the second run. The inlet conditions are the same as in Fig. 3. 


\section{Conclusion}

A new equation to predict the heat transfer coefficient was developed by comparing the experimental data to the numerical solution of the heat balance equations for both rice and air. One can also conclude from the above results of the factors which control the rate of drying, the ones connected with values of the heat transfer coefficient are much less influential than others, such as grain and air temperature, grain and air velocity, ... etc.

\section{List of Symbols}

a Particle surface area per unit volume, $\mathrm{m}^{2} / \mathrm{m}^{3}$

$C_{a} \quad$ Specific heat of dry air, $\mathrm{kJ} / \mathrm{kg}-{ }^{\circ} \mathrm{C}$

$C_{a v} \quad$ Volumetric specific heat of air, $\mathrm{kJ} / \mathrm{m}^{3}-{ }^{\circ} \mathrm{C}$

$C_{p} \quad$ Specific heat of dry grain kernel, $\mathrm{kJ} / \mathrm{kg}-{ }^{\circ} \mathrm{C}$

$C_{p v} \quad$ Volumetric specific heat of dry grain, $\mathrm{kJ} / \mathrm{m}^{3}-{ }^{\circ} \mathrm{C}$

$C_{s} \quad$ Specific heat of solid, $\mathrm{kJ} / \mathrm{kg}-{ }^{\circ} \mathrm{C}$

$C_{v} \quad$ Specific heat of water vapor, $\mathrm{kJ} / \mathrm{kg}-{ }^{\circ} \mathrm{C}$

$C_{w} \quad$ Specific heat of liquid water, $\mathrm{kJ} / \mathrm{kg}-{ }^{\circ} \mathrm{C}$

$G \quad$ Flow rate, $\mathrm{kg} / \mathrm{m}^{2}-\mathrm{h}$

$h_{c} \quad$ Convective heat transfer coefficient, $\mathrm{kJ} / \mathrm{m}^{2}-{ }^{\circ} \mathrm{C}-\mathrm{h}$

$\dot{h}^{\mathrm{c}} \quad$ Volumetric heat transfer coefficient, $\mathrm{kJ} / \mathrm{m}^{3}-{ }^{\circ} \mathrm{C}-\mathrm{h}$

$H \quad$ Absolute humidity, $\mathrm{kg} / \mathrm{kg}$

$\bar{M} \quad$ Average moisture content, dry basis (decimal)

$R_{a} \quad$ Solid-Gas ratio defined in Equation (1)

$t \quad$ Time, h

$T_{a} \quad$ Air temperature, ${ }^{\circ} \mathrm{C}$

$T_{a 0} \quad$ Initial air temperature, ${ }^{\circ} \mathrm{C}$

$T_{\text {exp }} \quad$ Experimental temperature, ${ }^{\circ} \mathrm{C}$

$T_{p} \quad$ Grain temperature, ${ }^{\circ} \mathrm{C}$

$T_{p 0}^{p} \quad$ Initial grain temperature, ${ }^{\circ} \mathrm{C}$

$V_{0} \quad$ Air velocity, $\mathrm{m} / \mathrm{h}$

$x \quad$ Variable bed coordinate, $\mathrm{m}$

$W_{a} \quad$ Weight rate of fluid, $\mathrm{kg} / \mathrm{h}$

$W_{s} \quad$ Weight rate of solid, $\mathrm{kg} / \mathrm{h}$

$\rho \quad$ Density, $\mathrm{kg} / \mathrm{m}^{3}$

\section{Subscripts}

$\begin{array}{ll}a & \text { Air } \\ p & \text { Product }\end{array}$

\section{References}

11 Barker, J.J., Heat transfer in packed beds, Ind. and Engr. Chem. 57(4): 43-51 (1965).

[2] Henderson, S.M. and Pabis, S., Grain drying theory, IV. The effect of air flow rate on drying index. J. Agr. Eng. Res. 7: 85-89 (1962)

[3] Treybal, R.E., Mass Transfer Operations, McGraw-Hill Book Co., N.Y., p. 63 (1955).

[4] Boyce, D.C., Grain moisture and temperature changes with position and time during drying. J. Agr. Eng. Res., 10(4): 333-341 (1965). 
[5] O'Callaghan, J.R., Menzies, D.J. and Bailey, P.H., Digital simulation of agricultural drier performance. J. Agr. Eng. Res., 16(3): 223-244 (1971).

[6] Bernard, W.G., George, T. and Hougen, O.A., Heat mass and momentum transfer in flow of gases through granular solids, Trans. Am. Inst. Engrs 39(1): pp. (1943).

[7] Schumann, T.E.W., Heat transfer: liquid flowing through a porous prism, J. Franklin Institute 208: 405-416 (1929).

[8] Thomas, G.B. and Harlod, R., A review of fluid-to-particle heat transfer in packed and moving bed, Chem. Eng. Prog. Sym. 57(32): 69-74 (1957).

[9] Wang, C.Y., Rumsey, T.R. and Singh, R.P., Convective heat transfer coefficient in a packed bed of rice, ASAE Paper No. 79-3040 (1979).

[10] Walker, L.P., Process Analysis of a Multistage Concurrent Flow Rice Dryer, Ph.D. Thesis, Michigan State University (1978).

[11] Huang, T.G. and Gunkel, W.W., Theoretical and experimental studies of heating front in a deep bed hygroscopic product, ASAE paper No. 72-374 (1972).

[12] Baker-Arkema, F.W., Lerew, L.E., Boer, S.F. and Roth, M.G., Grain dryer simulation, Research Report from the Michigan State University Agricultural Experimental Station, East Lansing, p. 6 (1974).

[13] Wang, C.Y., Simulation of Thin-layer and Deep Bed Drying of Rough Rice, Ph.D. Thesis, University of California, Davis (1978).

[14] Zahed, A.H., Simulation of Drying and Air Channelling in a Concurrent-flow Rice Dryer, Ph.D. Thesis, University of California, Davis (1982). 


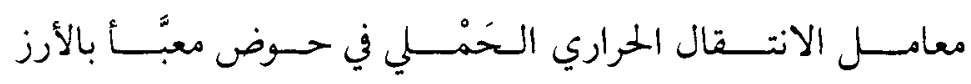

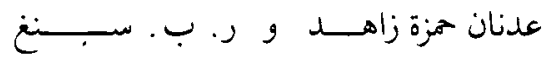

قسم الهندسة الكيميائية ، كلية الهندسة ، جامعة الملك عبد العزيز ، جــدة ، المملكة العربية السعودية ؛ رهاه

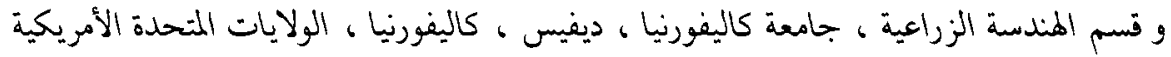

$$
\begin{aligned}
& \text { من خلال البحث ، تم إيجاد معادلة جديدة لمعامل الاتقال الحراري وذلك بمقارنة الثتائج }
\end{aligned}
$$

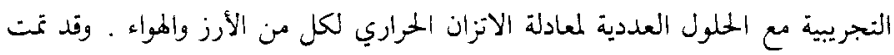

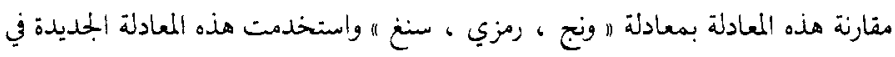

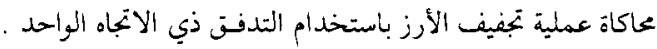

